\title{
MOLTEN SALT BLANKET CALCULATIONS FOR A TOKAMAK FUSION-FISSION HYBRID REACTOR
}

BY

D. L. CHAPIN

\section{PLASMA PHYSICS LABORATORY}

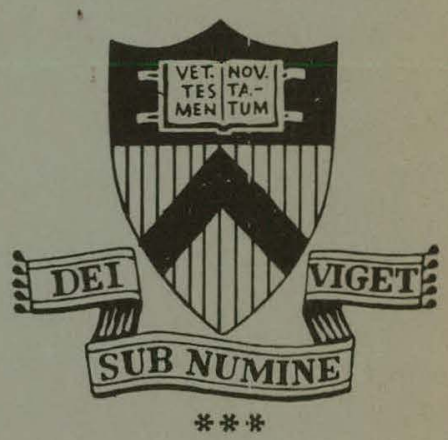

\section{PRINCETON

This work was supported by U. S. Energy Research and Development Administration Contract $\mathrm{E}(11-1)-3073$. Reproduction, translation, publication, use and disposal, in whole or in part, by or for the United States Government is permitted. 


\section{DISCLAIMER}

This report was prepared as an account of work sponsored by an agency of the United States Government. Neither the United States Government nor any agency Thereof, nor any of their employees, makes any warranty, express or implied, or assumes any legal liability or responsibility for the accuracy, completeness, or usefulness of any information, apparatus, product, or process disclosed, or represents that its use would not infringe privately owned rights. Reference herein to any specific commercial product, process, or service by trade name, trademark, manufacturer, or otherwise does not necessarily constitute or imply its endorsement, recommendation, or favoring by the United States Government or any agency thereof. The views and opinions of authors expressed herein do not necessarily state or reflect those of the United States Government or any agency thereof. 


\section{DISCLAIMER}

Portions of this document may be illegible in electronic image products. Images are produced from the best available original document. 


\section{NOTICE}

This report was prepared as an account of work sponsored by the United States Government. Neither the United States nor the United States Energy Research and Development Administration, nor any of their employees, nor any of their contractors, subcontractors, or their employees, makes any warranty, express or implied, or assumes any legal liability or responsibility for the accuracy, completeness or usefulness of any information, apparatus, product or process disclosed, or represents that its use would not infringe privately owned rights.

Printed in the United States of America.

Available from

National Technical Information Service

U. S. Department of Commerce 5285 Port Royal Road

Springfield, Virginia 22151

Price: Printed Copy $\$$ *; Microfiche $\$ 1.45$

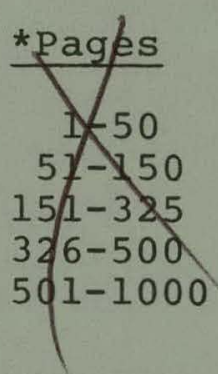

NTIS

Selling Price

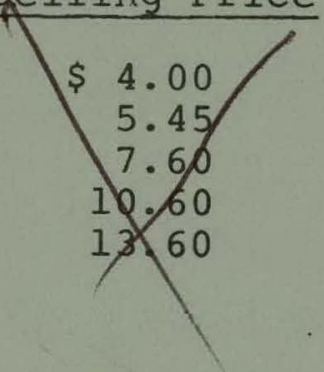


Molten Salt Blanket Calculations for a

Tokamak Fusion-Fission Hybrid Reactor

\begin{abstract}
D. L. Chapin
Princeton University Plasma Physics Laboratory

Princeton, New Jersey 08540
\end{abstract}

Abstract

Several possible blanket designs for use in a tokamak fusion-fission hybrid reactor are investigated. The main constituent of the blanket is a molten salt, possibly with a separate convertor region for multiplication of the source neutrons. Both the thorium and uranium fuel cycles are analyzed subject to constraints on the blanket performance such as high blanket energy multiplication and sufficient breeding of tritium and fissile fuel. It is found that the behavior depends strongly on the salt composition through the ratios of fertile material to fissile material and lithium to fissile material. It is also very important to have multiplication of the high energy source neutrons in a convertor zone between the plasma and the salt. Ways of optimizing this neutron multiplication through variations in the convertor zone composition and thickness are investigated. 


\section{Introduction}

In recent years there has been renewed interest in the concept of fusion-fission hybrid systems; that is, the surrounding of a D-T fusion plasma with a blanket containing uranium or other heavy elements. Such a scheme might be thought of for several reasons, such as to allow a reduction in the plasma confinement requirements through;. energy multiplication in the blanket or to serve as a breeder of fissile fuel for a fission reactor economy. 'l'wo recent review articles surnmarizing the development of hybrid concepts are given in references 1 and 2 .

A possible application of the fusion-fission hybrid for a tokamak plasma is that of the beam-driven. (two component) tokamak reactor $(\underline{3})$. Beam-driven tokamaiks will have $Q \simeq 1$, where $Q$ is the ratio of the fusion power to the beam power; but can still have a high fusion power density and hence provide a strong $14 \mathrm{MeV}$ neutron source(4). Conceivably, it might be possible to surround such a plasma with a high energy multiplication blanket, so that the beam-driven tokamak fusion-fission hybrid reactor would be economical even though the gain of the fusion core itself is sma11.

In this paper we investigate the neutronic performance of several possible blanket designs that might be used in such a beam-driven tokamak reactor. Although the 
two-component plasma does not specifically enter the blanket calculations, it does place the implicit requirement that the blanket energy multipliçation must be high.

For the study it was assumed that the main constitutent of the blanket was molten salt, possibly with a separate convertor region for multiplication of the source neutrons. The molten salt was chosen as the breeding medium for several reasons, such as ease of tritium removal and composition control with the salt and the ability to circulate the salt and remove the fission products and bred fissile fuel continuously, as is proposed in the Molten Salt Breeder Reactor (MSBR)( $\underline{5})$. Both the $\mathrm{U}^{238}-\mathrm{Pu}^{239}$ and. $\mathrm{Th}^{232}-\mathrm{U}^{233}$ fuel cycles are investigated subject to certain constraints on the blanket performance such as high energy multiplication and sufficient breeding of tritium and fissile fuel. Variations in the composition of the salt and the convertor were studied in an attempt to obtain the best neutronic performance.

\section{Blanket Calculational Model}

The hybrid blanket model used for the neutronics ca.l culation is shown in Fig. 1. The plasma 1s assumed to be a uniformily distributed source of radius $100 \mathrm{~cm}$, followed by a vacuum zone $50 \mathrm{~cm}$ thick. The total blanket thickness is $150 \mathrm{~cm}$, and is mainly composcd of 3 regions - the 
convertor, breeder, and shield. The convertor region, whose purpose is to multiply the $14 \mathrm{MeV}$ source neutrons, is taken to be $9 \mathrm{~cm}$ thick for all the calculations except some discussed in section VII. The breeder zone, where the tritium and most of the fissile fuel is bred, is $60 \mathrm{~cm}$ thick for all cases except some in section VII. A shield $80 \mathrm{~cm}$ thick and with composition $70 \%$ stainless steel, $25 \% \mathrm{~B}_{4} \mathrm{C}$, and 5\% He (volume percents) follows the breeder zone.

'The neutronics calculations were performed with the ANISN multigroup discrete ordinates neutron transport code(ㅁ). One-dimensional cylindrical geometry was used with an $\mathrm{S}_{8}$ angular quadrature and $\mathrm{P}_{3}$ expansion of the anisotropic scattering. A 30 group cross section set was prepared for the calculations by collapsing a 100 group set( $\underline{7}$ ) over a typical hybrid blanket spectrum.

III. Blanket Materials and Parameter Definitions

The two fuel cycles of interest for a fusion-fișion hybrid are the $\mathrm{U}^{238}-\mathrm{Pu}^{239}$ cycle and the $\mathrm{Th}^{232}-\mathrm{U}^{233}$ cycle. The pertinent decay chains are( $\underline{8})$

$$
\mathrm{U}^{238}(\mathrm{n}, \gamma) \rightarrow \mathrm{U}^{239} \frac{\beta^{-}}{23.5 \mathrm{~m}} \mathrm{~Np}^{239} \frac{\beta^{-}}{2.4 \mathrm{~d}} \mathrm{Pu}^{239}\left(2.4 \times 10^{4} \mathrm{y}\right)
$$

and 
$\operatorname{Th}^{232}(n, \gamma) \rightarrow \operatorname{Th}^{233} \frac{\beta^{-}}{22 \mathrm{~m}} \mathrm{~Pa}^{233} \frac{\beta^{-}}{27 \mathrm{~d}^{-}} \mathrm{U}^{233}\left(1.6 \times 10^{5} \mathrm{y}\right)$ 。

At the same time that fissile material is being bred by such reactions, it will be necessary to fission some material in the blanket in order to provide adequate energy multiplication.

It is the purpose of the convertor to provide some of these fissions in the elements $\mathrm{U}^{238}$ or $\mathrm{Th}^{232}$, which fission only at high neutron energies. Besides releasing energy, these fast fissions are excellent neutron multipliers, since approximately 4 neutrons are released per fission (at high energy). Other reactions of interest for neutron multiplication are the $(n, 2 n)$ and $(n, 3 n)$ reactions.

As will be studied, it may also be necessary to put some fissile materials, e.g. $\mathrm{Pu}^{239}$ or $\mathrm{U}^{233}$, in the blanket to obtain satisfactory energy multiplication. Since we are assuming a D-T plasma fuel sycle, il will of cuurse also be necessary to breed tritium through the reactions $\operatorname{Li}^{6}(n, \alpha) t$ and $\mathrm{Li}^{7}\left(\mathrm{n}, \mathrm{n}^{\prime} \alpha\right) \mathrm{t}$.

Thus there are a number of different processes that must compete for the available neutrons - neutron multiplication, fission, and breeding of tritium and fissile fuel. In figures $2-4$ we show some cross sections for these various reaction types. In figure 2 the most important reactions at high energies are shown - the fission and 
neutron multiplying reactions in $\mathrm{U}^{238}$ and $\mathrm{Th}^{232}$ and the $\mathrm{Li}^{7}$ tritium reaction. Note that $\mathrm{U}^{238}$ would seem to be a better convertor material than $\mathrm{Th}^{232}$ since its fission cross section is higher. In figures 3 and 4 the pertinent reaction cross sections from $.1 \mathrm{eV}$ to $10 \mathrm{keV}$ are plotted for the two fuel cycles along with the $\mathrm{Li}^{6}$ tritium reaction. Note that the fission cross sections for $\mathrm{Pu}^{239}$ and $\mathrm{U}^{233}$ àre fairly close to the $\mathrm{Li}^{6}$ cross section over most of this energy rangc. However, the breeding reactions in $\mathrm{y}^{238}$ and $\mathrm{Th}^{232}$ are smaller than the fission and $\mathrm{Li}^{6}$ cross sections at low energies: In the thermal group the $\mathrm{Th}^{232}$ capture cross section is over twice as large as the $U^{238}$, but $U^{238}$ has a fairly large resonance at $6-7 \mathrm{eV}$. It should be noted that these cross section plots in figures $2-4$ have been made from a 30 group set collapsed from a 100 group (infinitely dilute) library( 7$)$, and hence much of the detail :in the resonances has been lost. As such, they are intended only to illustrate the general trends in the cross sections of interest in a fusion-fission hybrid blanket.

Parameter Definition

Since there will clearly be a number of competing reactions in the blanket, it is of interest to define certain parameters that can be used to assess a particular blanket's performance. 
The first parameter is $\mathrm{T}$, the tritium breeding ratio, defined as the number of tritum atoms produced per source neutron. The obvious requirement is that $\mathrm{T}$ be greater than one, so that the blanket is self-sustaining in tritium production.

The second parameter is $M$, the blanket energy multiplication factor, defined as

$M=\frac{\text { (no. fissions per source neutron) } \times(200 \mathrm{MeV} / \mathrm{f} \text { ission })+E_{f}}{E_{f}}$

where $\mathrm{E}_{f}=14.1 \mathrm{MeV}$, the fusion neutron energy. $\mathrm{M}$ can be kept quite small ( 1$)$, as in the symbiotic system( 2 ), or quite large $(\simeq 40)$, as in an energy optimized blanket( $\underline{9})$, so long as the blanket is not critical. For the blankets analyzed in this study for use with a beam-driven tokamak, we shall require $M>10$ as a necessary condition for sufficient electricity production.

The third parameter is $\underline{F}$, the net number of fissile fuel atoms produced per source neutron. The requirement on $F$ is $F>0$, so that if some fissile fuel j.s in the blanket we must at least breed as much as we burn. lihus $F$ is the number of captures in the fertile material minus the number of absorptions in the fissile material.

$\Lambda$ related parameter is $\underline{C R}$, the blanket conversion ratio, defined by 


$$
\begin{gathered}
\because \\
\mathrm{CR}=\frac{\text { number of captures in fertile material }}{\text { number of absorptions in fissile material }}
\end{gathered}
$$

$F$ and $C R$ are not independent, so that if $F>0$ ? then $C R>1$. An important consideration in maximizing $F$ and $C R$ is $\alpha$, the capture-to-fission ratio for a fissile material(10). Thc lower the value of $\alpha$ is, the higher the probability is that, once a neutron is absorbed in a fissile nucleus, a fission event rather than a capture will occur. The values of $\alpha$ for $\mathrm{Pu}^{239}$ and $\mathrm{U}^{233}$ at two different energies (for the 30 group

\begin{tabular}{|c|c|c|}
\hline $\mathrm{E}$ & $\mathrm{U}^{233} \alpha$ & $\mathrm{Pu}^{239}$ \\
\hline $500 \mathrm{keV}$ & .063 & .048 \\
\hline $0.1 \mathrm{eV}$ & .090 & .392 \\
\hline
\end{tabular}
cross section set) are:

Hence, both elements have good values of $\alpha$ at high energies while for thermal energies $\mathrm{U}^{233}$ is much better than $\mathrm{Pu}^{239}$. These differences in $\alpha$ will be an important factor in the design of a molten salt blanket, since in such a blanket the neutron spectrum will be relatively soft due to the moderation by the light elements of the salt. i: 
IV. $\mathrm{UO}_{2}$ Convertor and Pu-U Salt

The first series of blanket calculations were done for a $\mathrm{UO}_{2}$ convertor zone $9 \mathrm{~cm}$ thick followed by. a $60 \mathrm{~cm}$ thick breeder zone of molten salt. The convertor zone was assumed to consist of stainless steel clad $\mathrm{UO}_{2}$ plates cooled by $\mathrm{He}$, with volume fractions of $55 \% \mathrm{UO}_{2}, 12 \%$ steel, and $33 \%$ He. The breeder zone was composed of $5 \%$ (volume) stainless steel structure plus varying mixtures of salt and graphite (C). The steel composition for all cases was $17 \% \mathrm{Cr}, 12 \%$ $\mathrm{Ni}$, and $71 \% \mathrm{Fe}$ (atom percents).

The molten salt used in these calculations was LiF $\mathrm{BeF}_{2}-\mathrm{UF}_{4}-\mathrm{PuF}_{3}$ with varying mole percents of $\mathrm{UF}_{4}$ and $\mathrm{PuF}_{3}$. The $\mathrm{Li}^{6}$ atom percent in $\mathrm{Li}$ was also varied in the study, with natural $\mathrm{Li}$ being $7.4 \% \mathrm{Li}^{6}$. The uranium in the salt (and also in the convertor) was always used as depleted in $\mathrm{U}^{235}(0.3 \%)$. The melting point for these molten salts will be in the region of $450^{\circ} \mathrm{C}$, which would perhaps be an important factor in a consideration of their use in a hybrid blanket.

In Table 1 we show the performance of eight blankets with a $\mathrm{UO}_{2}$ convertor and U-Pu salt breeder. The convertor composition is held constant while the mole composition of the salt, the $\mathrm{Li}^{6}$ atom percent in $\mathrm{Li}$, and the salt-C volume fractions are varied. Shown for each blanket are T, M, F, $\mathrm{CR}$, and the total blanket energy per source neutron (equal to $\mathrm{M} \times 14.1 \mathrm{MeV})$. 
Cases 1 and 2 in Table 1 investigate the effect of changing the salt-C mixture in the breeder zone for a salt with 6 mole percent $\mathrm{UF}_{4}$ and no $\mathrm{Pu}$. It is seen that raising the salt volume fraction from $15 \%$ to $95 \%$ causes a small increase in $T, M$, and $F$, which is due mostly to the harder neutron spectrum in case 2 with no $C$. This faster spectrum produces more fast fissions in $U^{238}$ and $(n, 2 n)$ reactions in Be, thus sightly increasing the number of neutrons available in the blanket, However, both of these blankets are unsuitable due to the low values of $T$ and $M$. The $\mathrm{Li}^{6}$ atom percent could be increased over that in case 2 , so that $\mathrm{T}$ could be made greater than 1 and $F$ would be about 0.6 . This would be satisfactory except for the low value of $M$.

Most all of the energy multiplication in cases 1 and 2 comes from the $\mathrm{UO}_{2}$ convertor, which produces about 0.2 fissions per: source neutron or $40 \mathrm{MeV}$. This convertor yields a net gain of about 0.8 neutrons per source neutron from these fissions and from $(n, 2 n)$ and $(n, 3 n)$ reactions, which are then distributed between $T, F$, and parasitic losses. (Ways to improve the convertor performance are studied in section VII). Since this is not sufficient to meet the requirement $M>10$, it was decided to introduce some fissile fuel in the salt to produce more fissions and raise the blanket energy.

The results of using 1 mole percent $\mathrm{PuF}_{3}$ in the salt are shown as case 3 in Table 1 . Here we use no graphite in 
the breeder zone and natural Li. Adding the $\mathrm{Pu}$ doubles $\mathbb{M}$ relative to case 2 and also raises $T$, with a subsequent decrease in $\mathrm{F}$ due to the fissioning of the $\mathrm{Pu}$. This blanket is unsatisfactory for two reasons - $T$ and $M$ are too low. Even though $T$ was low in case 3 , it was thought that if there was less $\mathrm{Li}^{6}$ in the blanket more fissions in the $\mathrm{Pu}$ might occur, thus releasing more neutrons and possibly raising $\mathrm{T}$.

The blanket performance when the $\mathrm{Li}^{6}$ atom fraction is cut to $0.5 \%$ is shown as case 4 in Table 1 . We can see that $M$ is increased by $50 \%$ over case 3 , to 12.1 , and $F$ increases to 1.18. However, $\mathrm{T}$ is now reduced to .131 ; partly as the result of the lower concentration of $\mathrm{Li}^{6}$ but also because there is now too much $\mathrm{U}^{238}$ in the salt. Thus, while there are more fissions in the salt too many of the fission neutrons are being captured in the $\mathrm{U}^{238}$ before they are able to slow down to thermal energies and either breed tritium or produce more fissions. The relavent cross sections for this three-way competition for the neutrons can be seen in figure 3 .

Because of this dominance of the $U^{238}$ in case 4 , it was decided to reduce the mole fraction of $\mathrm{UF}_{4}$ to $1 \%$. The results of this blanket are shown as case 5 in Table 1 , where the $\mathrm{Li}^{6}$ fraction is still $0.5 \%$. Now we see that many more $\mathrm{Pu}$ fissions are occurring so that $\mathrm{M}$ rises to 33.9 . $\mathrm{T}$ has also increased, to .4, but now $F$ is negative and the 
blanket conversion ratio is only 0.7 . Thus, we have the undesirable situation of burning more $\mathrm{Pu}$ than we breed more than one $\mathrm{Pu}$ atom is needed than is produced per source neutron. Hence it, would appear that now we have too little $\mathrm{Li}^{6}$ in the blanket, - not enough tritium is being bred and too much pu is being burned.

In cases 6-8 in Table 1 we show the results of steadily increasing the $\mathrm{Li}^{\mathrm{O}}$ atom percent with the same salt composition as in case 5 . In case 6 , where the $\mathrm{Li}^{6}$ is increased by a factor of four over case 5 , we see the $T$ has nearly doubled and that $F$ has increased, although it is still less than zero. As expected, M decreases since more neutrons are being absorbed in the $\mathrm{Li}^{6}$ than in the Pu. Raising the $\operatorname{Li}^{6}$ to 3 atom percent (case 7 ) produces a near break-even in fissile fuel production $(\mathrm{CR}=.99)$, but. $\mathrm{T}$ is still less than 1 and $M$ has decreased to 16.6. Finally, in case 8 with $6 \% \mathrm{Li}^{6}$ we achieve $\mathrm{T}>1$ and $\mathrm{F}=0.26$. with multiplication $\mathrm{M}=11.6$, thus meeting all requirements on $\mathrm{T}$, F, and M. Certainly, $T$ is too close to 1 when possible reactor geometric losses are considered, and $F$ is probably too low to have a significant benefit in the economics. Also, the $6 \% \mathrm{Li}^{6}$ is so close to natural $\mathrm{Li}$ that it would be better to use natural Li, which would thus raise $\mathrm{T}$ somewhat while lowering $\mathrm{F}$ and $\mathrm{M}$.

Hence, these results illustrate that a blanketiwith a $\mathrm{UO}_{2}$ convertor and $\mathrm{Pu}-\mathrm{U}$ salt breeder can achieve adequate 
(break-even) tritium and fissile fuel breeding with a blanket energy multiplication factor of 10-12. Subsequent sections will investigate improvements on this performance using different convertor and molten salt compositions.

V. All Pu-U Salt Blanket

In this section we investigate blankets with a $\mathrm{Pu}-\mathrm{U}$ salt in which the salt is used in both the convertor and breeder zones. It was considered impractical to use two different salt compositions in the same blanket, so the same salt was used in both zones. To maintain the hardest neutron spectrum, we used the convertor zone as $95 \%$ salt and $5 \%$ steel, with no graphite.

In Table 2 the results of four blankets with all $\mathrm{Pu}-\mathrm{U}$ salt are shown. Case 9, with the same salt as case 8 except with natural Li, yields a tritium breeding ratio $\mathrm{T}$ of 1.5 and energy multiplication $\mathrm{M}=10$. However, its conversion ratio is only 0.24 and is thus a consumer of fissile fuel. In an attempt to lower $T$ and raise $F$, we next cut the $\mathrm{Li}^{6}$ to 2 atom percent, shown as case 10. Instead of decreasing $\mathrm{T}$, we see that it increases to nearly 2.0 and $M$ rises to 42.5 (probably close to critical) because now there are many more $\mathrm{Pu}$ fissions in the blanket producing more neutrons and energy. However, again $\mathrm{F}$ is less than zero and the blanket is a net consumer of fissile fuel. In case 11 the results of cutting the $\mathrm{PuF}_{3}$ mole fraclion in half are shown. Now we 
see that $T$ and $M$ decrease, that is there are fewer fissions in the blanket, while $F$ increases relative to caise 10 , although it is still negative. Note that the conversion ratio has doubled from cases 9 and 10 to case 11, indicating an approximately linear dependence between $\mathrm{CR}$ and the ratio of $\mathrm{U}$ to $\mathrm{Pu}$ in the salt.

For the final run in this series, shown as case: 12 in Table 2, the salt composition has been changed so that the $U$ to $\mathrm{Pu}$ ratio is 5. For this blanket the CR is 1.37, i.e. about 5 times that of cases 9 and 10 with a $U$ to $P u$ ratio of 1 ; and there is a small net breeding of fissile fuel. However, $\mathrm{T}$ is less than 1 and the blanket energy is small. $\mathrm{T}$ could be made greater than 1 for the salt in case 12 by raising the $\mathrm{Li}^{\dot{6}}$ percent, but this would then cause a further reduction in mas more neutrons are used to breed tritium. Using less salt and more graphite in the breeder zone would also be undesirable, since there would be a softer neutron spectrum which:would lower $F$ and $C R$ because of the higher value of $\alpha$ for $\mathrm{Pu}$ at lower energies.

Thus an all $\mathrm{Pu}-\mathrm{U}$ salt blanket would not appear to be useful with a beam-driven tokamak, since $M$ would probably be less than 4 with sufficient breeding. The main reason for this is that it is not possible to produce enough neutron multiplication from $\mathrm{U}^{238}$ with this salt convertor. For example, in case 12 there are only $.01 \mathrm{U}^{238}$ fissions per source neutron in the blanket, while with the $\mathrm{UO}_{2}$ convertor 
there were 0.2 in the convertor alone. As is well known, it is possible to build a breeder reactor using the $\mathrm{Pu}-\mathrm{U}$ fuel cycle only for a hard neutron spectrum, which would be difficult to maintain in a molten salt blanket. Even with a good spectrum, the hybrid blanket is further burdened by the necessity to breed tritium, so that without neutron multiplication an all $\mathrm{Pu}-\mathrm{U}$ salt blanket seems unsuitable for this study. However, somewhat better performance might be obtained with a Th-U salt in a thermal spectrum, and is studied in the next section.

VI. All Th-U ${ }^{233}$ Salt Blanket

It was next of interest to investigate a molten salt hybrid blanket based on the Th-U ${ }^{233}$ fuel cycle. Due to the low value of the Th fast fission cross section (Fig. 2), it was decided not to try a separate convertor region of $\mathrm{ThO}_{2}$ or other material but instead to use an all salt blanket. The convertor region in all cases was chosen to be $95 \%$ salt so as to obtain. the hardest spectrum possible for that zone. The results of six all Th-U salt blankets are shown in Table 3. The salt composition in cases 13-15, with about 12 mole percent $\mathrm{ThF}_{4}$, is similar to that proposed for use in the MSBR( $\underline{5})$. Also, the volume fractions of $40 \%$ salt and $55 \%$ graphite in the breeder zone are similar to the MSBR. The blanket in case 13 , with no $\mathrm{U}^{233} \mathrm{~F}_{4}$ and natural Li, produces 
very few fissions in the Th and hence a very low $M$. There is consequently little neutron multiplication in the blanket, with. the sum of $F$ and $T$ being only about 1.2; and thus it is neçessary to add some fissile material to the blanket.

In case 14 we use 0.2 mole percent $U^{233} F_{4}$ in the blanket, which produces a slight increase in M over case 13 but still a véry low value. This salt is nearly the same as that in the MSBR except for the natural Li (the MSBR uses no $\mathrm{Li}^{6}$ in the salt). In case 15 we show the results when the $\mathrm{Li}^{6}$ is reduced to $2 \%$. Again we tind a sma $\perp \perp$ rise in $\tilde{y}$, wi a lower $\mathrm{T}$ and higher $\mathrm{F}$. The reason there are so few fissions and resultant low $M$ in cases 14 and 15 is the relatively high concentration of $T h$ in the salt as compared to $\mathrm{Li}^{6}$ and $\mathrm{U}^{233}$. Note that the $\mathrm{CR}$ is about the same in both blankets (12.7) and so is the ratio of $\mathrm{Th}$ to $\mathrm{U}$ $(12.3 \div 0.2=61.5)$. This might be expected, since the $\mathrm{Th}$ density determines the fissile production while the U density determines the fissile burn-up. If there is an approximately Linear dependence of $\mathrm{CR}$ on the $\mathrm{Th}$ to $\mathrm{U}$ ratio for an all salt blanket, as in the previous section with the $\mathrm{Pu}-\mathrm{U}$ salt, theñ for $\mathrm{CR}=1$ the $\mathrm{Th}$ to $\mathrm{U}$ ratio should be about $61.5 \div 12.7=4.8$.

In cases 16-18 of Table 3 we show the results of varying the $\mathrm{Li}^{6}$ density for a salt with a Th to $U^{233}$ !ratio of 4.8. As can be seen, for the three blankets the $C R$ is 
constant at about 1 and $F$ is slightly greater than zero, regardless of the $\mathrm{L}_{1}^{6}$ atom percent. Note. that as the $\mathrm{Li}^{6}$ is increased we see the expected trend of $T$ increasing and $M$ decreasing as more of the neutrons are absorbed in the lithium and less in the uranium. The cross sections of these competing reactions are shown in Fig. 4. This trend could be continued in order to produce $T>1$, but the multiplication would drop to 10 or. less and there would just be break-even on the fissile fuel - i.e. probably an unattractive blanket for use with a beam-driven tokamak. Thus, it would appear to be necessary to have neutron multiplication in the convertor zone in order to achieve satisfactory performance in a molten salt blanket. This would seem reasonable, since without the multiplication we would be trying to design a driven subcritical breeder reactor that must also breed tritium and produce energy clearly a difficult task. Ways to increase the performance of the convertor zone are investigated in the next section.

VII. Convertor Zone Variations

In this section the convertor zone composition and thickness will be varied to see how the neutron multiplication in that region can be improved. For a reference blanket we will use case 8 of Table 1 , which had a $\mathrm{UU}_{2}$ convertor zone $9 \mathrm{~cm}$ thick followed by a molten salt 
breeder zone $60 \mathrm{~cm}$ thick. The salt composition, which is held constant while the convertor is changed, is Lị (50 mole \%) $-\mathrm{BeF}_{2}(48 \%)-\mathrm{UF}_{4}(1 \%)-\mathrm{PuF}_{3}(1 \%)$, with 6:atom \% $\mathrm{Li}^{6}$ in the Li. "The breeder zone volume fractions are $95 \%$ salt and 5\% stainless steel. The uranium in all cases (for both the convertor and breeder zones) is assumed to be depleted in $\mathrm{U}^{235}(0.3 \%)$.

In Table 4 the results of five different convertors with this salt are shown. 'l'he first blanket, case. 8 of Table 1 (discussed in section IV). is for a $\mathrm{UO}_{2}$ convertor with volume fractions $55 \% \cdot \mathrm{UO}_{2}, 12 \%$ steel, and $33 \% \mathrm{He}$. 'Shown in Table 4 are $T, M, F, C R$, and the blanket energy released per source neutron; plus two additional quantities - the number of convertor fissions per source neutron and the ratio $R_{U}$ of the $U^{238}$ number density in the convertor to the total number density in the convertor.

In case, 19 we have replaced the $\mathrm{UO}_{2}$ convertor... with UC, but kept the same volume fractions and thickness in the convertor. Ụsing the UC increases the $\mathrm{U}^{238}$ density Craction $R_{U}$ to 0.38 and produces about $20 \%$ more fissions in the convertor relative to the $\mathrm{UO}_{2}$ case. These extra fissions in turn result in.a slightly higher $\mathrm{T}$ and $\mathrm{F}$, with $M$ increasing to 12.6. Thus the UC blanket of case 19 would seem to satisfy fairly well the criterion established for the : study - large $M$ with sufficient tritium and fissile fuel breeding. 
Another possibility that would further increase $R_{U}$ would be the use of uranium metal in the convertor. Although the melting point of U-metal is less than ceramics such as $\mathrm{UO}_{2}$ or UC, it might be possible to obtain sufficient cooling by using stainless steel clad U-metal pellets or balls in large helium cooled pressure tubes. To compute volume fractions for such a convertor, a three layer pressure tube arrangement was assumed, providing a packing fraction of about $82 \%$. For high pressure helium the pressure tubes must be fairly thick, which results in a stainless steel volume fraction of about $21 \%$. To obtain an approximate upper and lower limit on the U-metal fraction, we may consider the pellets to either be solid or have a hole in the center through which helium flows. If there is a hole in the pellet, then the U-metal volume fraction is about $33 \%$, the $\mathrm{He}$ is $42 \%$, and the total steel (clad plus tube wall) is $25 \%$. With a solid pellet, there would be about $10 \% \mathrm{U}, 21 \%$ stainless steel, and $36 \%$ He. Hence one disadvantage of this type of convertor is that the steel volume fraction is about twice that of the UO $\mathrm{UO}_{2}$ and UC convertors, although there is an absence of the lighter elements oxygen and carbon and thus less moderation of the $14 \mathrm{MeV}$ neutrons.

It should be noted that this discussion of the configuration of a U-metal convertor was intended only to 
provide an approximate upper and lower bound on the volume fraction of uranium that might be possible in such a ischeme. A detailed study of heat transfer and structural requirements would be needed for a complete design. "Also, this convertor would clearly be a very heterogeneous structure; however, for these calculations a homogenized medium nust be assumed. Nonetheless, it is interesting to see if the U-metal convertor does produce better blanket performance than with the $\mathrm{UO}_{2}$ and $\mathrm{UC}$ convertors.

In cases 20 and 21 of Table, 4 we compare the results of two $9 \mathrm{~cm}$ thick U-metal convertors, one with $33 \% \mathrm{U}$ and the other with $40 \%$. For the $33 \% \mathrm{U}$ case, we see that the uranium is about $43 \%$ of the convertor number density but produces only . 21 convertor fissions - more than $\mathrm{UO}_{2}$ but less than UC. The blanket multiplication is about the same as the UC, but the sum of $T$ and $F$ is less due to the fewer number of fissions in the convertor. When we go to the $40 \%$ U-metal, shown as case 21, the convertor fissions increase and there is a higher $M$ and $F$, although $T$ is the same. This is fairly close to the UC convertor in the neutron multiplication, but now more neutrons are absorbed in. the $\mathrm{Li}$ and $\mathrm{Pu}$ and $\mathrm{less}$ in the U. This may be due in part to the convertor thickness, since with the U-metal convertor the magnitude of the uranium density is less than with the UO ${ }_{2}$ or UC even though the fraction $\mathrm{R}_{\mathrm{U}}$ is higher. Hence the optical thickness of the convertor is smaller and more of the $14 \mathrm{MeV}$ neutrons are 
able to penetrate into the molten salt breeder zone without reacting in the convertor.

As a final case, we attempted to increase the performance of the $40 \%$ U-metal convertor by making it $19 \mathrm{~cm}$ thick with a breeder zone $50 \mathrm{~cm}$ thick. The results are shown as case 22 in Table 4 , where we see that the convertor fissions have now risen to about 0.35 , or almost $45 \%$ more than with the $9 \mathrm{~cm}$ convertor (case 21). However, both $M$ and $\mathrm{T}$ have descreased while $\mathrm{F}$ has increased by a factor of four. Evidently, the thicker region has resulted in most of the convertor fission neutrons being captured in the uranium in the convertor before they are able to escape into the salt breeder zone. This was found to be the case; that is, the leakage from the convertor into the salt zone was about $18 \%$ smaller for the thicker convertor while the $U^{238}$ captures were $53 \%$ larger. Increasing the salt zone thickness would not be effective in raising $T$ and $M$, since there is approximately the same neutron leakage (.18 neutrons per source neutron) into the shield for both breeder zone thicknesses, i.e. most of the neutron absorption in the salt has taken place in the first $40-50 \mathrm{~cm}$.

Probably the best way to raise the tritium breeding and energy multiplication in a blanket similar to case $2 \%$ would be to increase the $\mathrm{Pu}$ and perhaps the $\mathrm{Li}^{6}$ density in the salt. This would allow more $\mathrm{Pu}$ fissions in the breeder zone and thus raise $T$ and $M_{0}$. There would of course be more 
burn-up of the $\mathrm{Pu}$ and $\mathrm{F}$ would decrease, but there would appear to be sufficient fissile breeding in the convertor zone to produce a blanket with high multiplication and adequate tritium and fissile fuel breeding.

If $i t$ was undesirable to increase the $\mathrm{Pu}$ concentration; another alternative would be to use a convertor thickness somewhere between that of cases 21 and 22 - e.g. $15 \mathrm{~cm}$. This might allow both more convertor fissions andmore leakagc into the salt and produce an increase in $T, F$, and $M$ over case 21 . However, even with the $9 \mathrm{~cm}$ convertor the U-metal and UC are better than the $\mathrm{UO}_{2}$, although they both are based on more advanced technology. :

\section{Conclusions}

In this paper we have investigated several possible blanket designs for use with a beam-driven tokamak fusion-fission hybrid reactor. The basic breeding material was a molten sâlt, possibly preceded by a separate convertor region. Both" the $\mathrm{U}^{238}-\mathrm{Pu}$ and $\mathrm{Th}-\mathrm{U}^{233}$ fuel cycles were considered, subject to the requirements of sufficient tritium ( $T$ ) and fissile fuel (F) breeding. Since the beam-driven plasma will only be break-even itself, another constraint was that the blanket energy multiplication Mimust be 10 or greater in order to provide adequate power gencration. 
A sequence of cases was studied for a $\mathrm{UO}_{2} \mathrm{He}$ cooled convertor zone followed by a breeder zone of molten salt on the U-Pu fuel cycle. While the convertor was held fixed, thus providing the same neutron multiplication for each blanket, the composition of the salt was varied by changing the $\mathrm{Pu}, \mathrm{U}$, and $\mathrm{Li}^{6}$ densities until a blanket with $\mathrm{T} \simeq 1$, $F=0.26$, and $M=11.6$ was obtained。

All salt blankets, i.e. without a separate convertor zone, were also studied for blankets based on both fuel cycles. To achieve net fissile fuel production with the U-Pu salt, the largest $M$ was only about 4. The performance in an all Th-U salt blanket was just slightly better break-even in fissile fuel with $M 10$ or less. The conversion ratio in the all salt blankets was found to be approximately linear with the ratio of fertile to fissile material, so that once this point was reached the $\mathrm{Li}^{6}$ density could be varied to achieve $\mathrm{T} \simeq 1$. However, as this was done $M$ would necessarily decrease to values unacceptable for a beam-driven tokamak.

It thus became apparent that to obtain the required $T, F$, and $M$ with a molten salt blanket, it would be necessary to have a separate convertor region to take advantage of the $14 \mathrm{MeV}$ neutrons for use in neutron multiplying reactions in $\mathrm{U}^{238}$. Different convertor materials and thiclnesses were investigated with a U-Pu salt breeder. It was found that, as expected, both UC and 
U-metal were, better convertor materials than $\mathrm{UO}_{2}$. The size of the convertòr zone was also important - if it is too thin some of the 'source neutrons may penetrate directly into the salt without interacting in the convertor. However, $:$ if it is too thick most of the excess neutrons may be absorbed in the convertor instead of leaking into the breeder.

Thus, : the most intercsting of the hlankets "studied here for use with a beam-driven tokamak would be one: with a U-metal convertor and a U-Pu molten salt breeder. The energy multiplication would be about 13 with net ffissile fuel production of about 0.25 atoms per source neutron, which could be somewhat improved with a thicker convertor. Another possibly might be to use a $\mathrm{Th}-\mathrm{U}^{233}$ salt in the breeder zone with a U-metal convertor. Since the neutron spectrum will tend to be soft due to the light elements in the salt, this fuel cycle would probably yield .better performance than the $\mathrm{U}^{233}-\mathrm{Pu}$. This blanket would also have the advantage of using the better known technology of the Th salt used in the Molten Salt Reactor Experiment(ㅁ). "There would be breeding of two fuels - $\mathrm{Pu}^{239}$ in the convertor and $\mathrm{U}^{233}$ in the salt - but since the convertor and breeder would be separate zones they would each require their own reprocessing cycles anyway. The performance of this bianket design, and optimization of the cases reported in this work, will be investigated in future studies. 
$-25-$

\section{Acknowledgment}

This work was supported by Energy Research and Development Administration Contract E(11-1)-307.3 


\section{$\underline{\text { References }}$}

1. B. R. Leonard, Jr., "A Review of Fusion Fission (Hybrid) Concepts", Nuclear Tech. 20, 161 (1973).

2. L. M. Lidsky, "Fusion-Fission Systems: Hybrid, Symbiotic, and Augean", Nucl。Fusion 15, 151 (1975).

3. D. L. Jassby, "Beam-Driven Tokamak Fusion-Fission Hybrid Reactor", Princeton Plasma Physics Laboratory Report MATT-1115 (1975)。

4. D. L。 Jassby, "Optimization of Fusion Power Density in the Two-Energy-Component Tokamak Reactor", Nucl. Fusion 15, 453 (1975).

5. M. W. Rosenthal, P. N. Haubenreich, and R. B. Briggs, "The": Development Status of Molten-Salt Breeder Reactors", Oak Ridge National Laboratory Report ORNL-4812 (1972).

6. W. W。 Engle, Jr., "A.User's Manual for ANISN", Oak Ridge Gasëous Diffusion Plant Report K-1693 (1967).

7. "1.00 Group Neutron Cross-Section Data Based on ENDF/B", DLC-2F, RSIC Data Library Collection, Oak Ridge National Laboratory (1975)。 
8. C. M. Lederer, J.M. Hollander, and I. Perlman, Table of Isotopes, 6 th Ed., (Wiley and Sons, Inc., New York, 1967).

9.: W. C. Wolkenhauer, et.al., "Status Report: Mirror Hybrid Reactor Studies", Pacific Northwest Laboratories Report BINWL-1835 (1974).

10. J. Jo Duderstadt and L. J. Hamilton, Nuclear Reactor Analysis (Wiley and Sons, Inc. New York, 1976) p. 59 . 


\begin{tabular}{|c|c|c|c|c|c|c|c|c|c|c|c|c|}
\hline $\begin{array}{l}\text { Case } \\
\text { No. }\end{array}$ & $\begin{array}{r}\mathrm{S} \\
\mathrm{LiF}\end{array}$ & $\begin{array}{l}\text { It Cor } \\
\mathrm{Mc} \\
\mathrm{BeF}_{2}\end{array}$ & $\begin{array}{l}o s i \\
e^{\circ} \% \\
U^{\prime} \\
4\end{array}$ & $\begin{array}{l}\text { ion } \\
L^{\mathrm{PuF}_{3}}\end{array}$ & $\begin{array}{r}\text { Bree } \\
\text { V } \\
\text { Salt. }\end{array}$ & $\begin{array}{l}\text { Zone } \\
\text { ne } \% \\
\text {. C. }\end{array}$ & $\left|\begin{array}{l}\mathrm{Li}^{b} \text { atom } \\
\text { percent } \\
\text { in } \mathrm{Li}\end{array}\right|$ & $\mid \begin{array}{c}\text { Tritons } \\
\text { T** }\end{array}$ & $\begin{array}{l}\text { Energy } \\
(\mathrm{MeV})^{*}\end{array}$ & $\begin{array}{c}\text { Multiplication } \\
M\end{array}$ & $\begin{array}{c}\text { Net } \text { Fissile } \\
\text { F* }\end{array}$ & $\begin{array}{c}\text { Conversion } \\
\text { Ratio CR }\end{array}$ \\
\hline 1 & 50 & 44 & 6 & - & 15 & 80 & (natural) & .378 & 56.2 & 4.0 & 1.19 & - \\
\hline 2 & 50 & 44 & 6 & - & 95 & 0 & 7.4 & .534 & 59.1 & 4.2 & 1.23 & $1331=81$ \\
\hline 3 & 50 & 44 & 5 & 1 & 95 & 0 & 7.4 & .703 & 118.9 & 8.4 & .88 & $\because 2.84$ \\
\hline 4 & 50 & 44 & 5 & 1 & 95 & 0 & 0.5 & .131 & 170.4 & 12.1 & 1.18 & 2.30 \\
\hline 5 & 50 & 48 & 1 & 1 & 95 & 0 & 0.5 & .403 & 477.9 & 33.9 & -1.10 & .70 \\
\hline 6 & 50 & 48 & 1 & 1 & 95 & 0 & 2.0 & .759 & $2 \varepsilon 6.0$ & 20.3 & -.22 & .89 \\
\hline 7 & 50 & 48 & 1 & 1 & .95 & 0 & 3.0 & .866 & $2 \Xi 4.7$ & 16.6 & -.0 .1 & .99 \\
\hline 8 & 50 & 48 & 1 & 1 & 95 & 0 & 6.0 & 1.021 & $1 \in 3.5$ & 11.6 & .26 & 1.29 \\
\hline
\end{tabular}

* Per source neutron.

Table 1. Blankət performance for various U-Pu salt and breëder zone zompositions. Convertor is $55 \% \mathrm{UD}_{2}, 12 \%$ stainless steel, and $33 \%$...He (volume percents). The uranium is depleted $(0.3 \%) U^{235}$. 


\begin{tabular}{|c|c|c|c|c|c|c|c|c|c|c|c|c|}
\hline $\begin{array}{l}\text { Case } \\
\text { No. }\end{array}$ & $\left|\begin{array}{r}\text { Sal } \\
\text { LiF }\end{array}\right|$ & $\begin{array}{l}\text { It Com } \\
\mathrm{Mo} \\
\mathrm{BeF}_{2}\end{array}$ & $\begin{array}{l}\text { ositi } \\
\mathrm{e} \% \\
\mathrm{UF}_{4}\end{array}$ & $\begin{array}{l}\text { ion } \\
\mathrm{PuF}_{3}\end{array}$ & $\begin{array}{r}\text { Breed } \\
\text { Vo } \\
\text { Salt }\end{array}$ & $\begin{array}{l}\text { Zone } \\
\text { 1e } \% \\
\text {. C }\end{array}$ & $\left|\begin{array}{l}\mathrm{Li}^{6} \text { atom } \\
\text { percent } \\
\text { in Li. }\end{array}\right|$ & $\begin{array}{l}\text { Tritons } \\
\text { T.T. }\end{array}$ & $\mid \begin{array}{l}\text { Energy } \\
(\mathrm{MeV})^{*}\end{array}$ & $\left.\right|_{M} ^{\text {Multiplication }}$ & $\begin{array}{c}\text { Net Fissile } \\
\text { F* }\end{array}$ & $\mid \begin{array}{c}\text { Conversion } \\
\text { Ratio CR }\end{array}$ \\
\hline 9 & 50 & 48 & 1 & 1 & 95 & 0 & 7.4 & 1.504 & 140.5 & 10.0 & -.80 & .24 \\
\hline 10 & 50 & 48 & 1 & 1 & 95 & 0 & 2.0 & 1.958 & 599.1 & 42.5 & -3.81 & .26 \\
\hline 11 & 50.5 & 48 & 1 & .5 & 95 & 0 & 2.0 & .953 & 148.1 & 10.5 & -.54 & .54 \\
\hline 12 & 50.5 & 48 & 1.25 & .25 & 95 & 0 & 2.0 & .713 & 63.8 & 4.5 & .16 & 1.37 \\
\hline
\end{tabular}

* Per source neutron.

Table 2. Blanket performance in an all U-Pu salt blanket with varying salt compositions. The convertor zone is $95 \%$ salt, $5 \%$ structure. The uranium is depleted $(0.3 \%) \mathrm{U}^{235}$. 


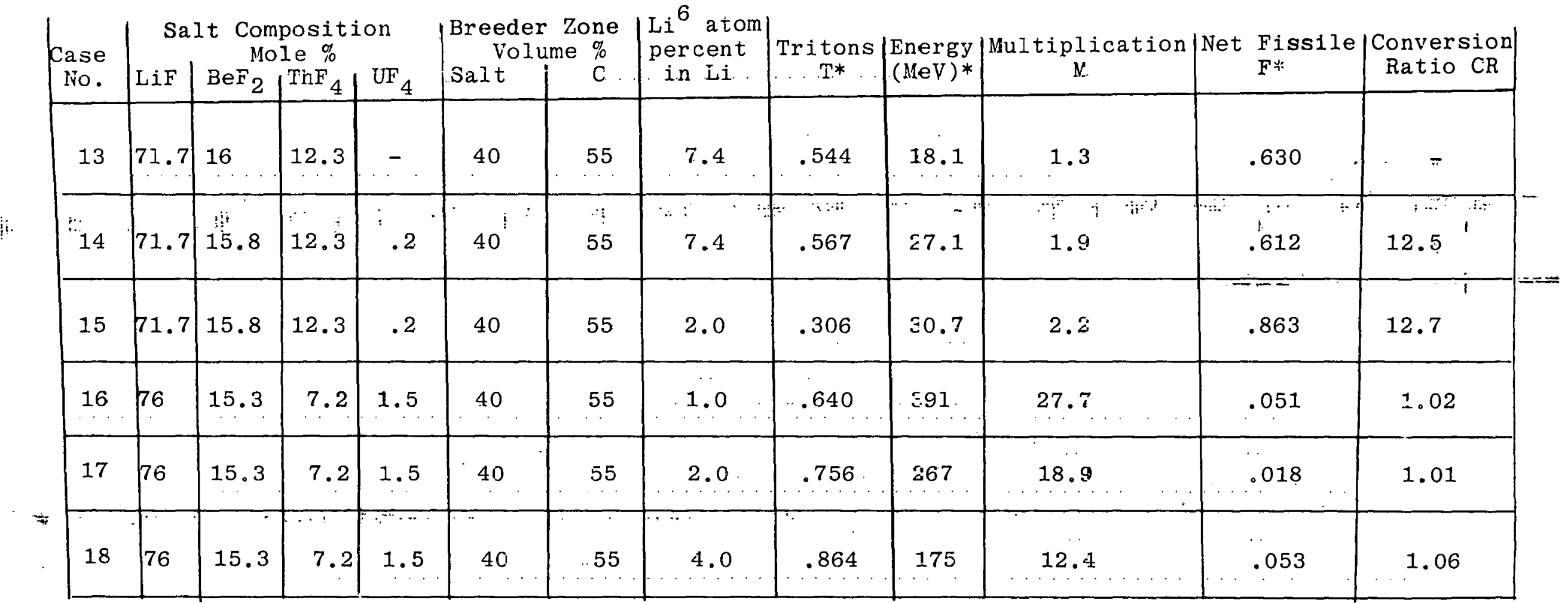

\footnotetext{
* Per source neutron.
} 


\begin{tabular}{|c|c|c|c|c|c|c|c|c|c|c|}
\hline $\begin{array}{l}\text { Case } \\
\text { Ho. }\end{array}$ & $\begin{array}{r}\text { Zone Th } \\
\text { Cconvertor }\end{array}$ & $\begin{array}{l}\text { ckness } \\
\text { Ereeder }\end{array}$ & $\begin{array}{l}\text { Convertor } \\
\text { Materials }\end{array} \mid$ & $\frac{\mathrm{N}^{23}}{\mathrm{U}_{\mathrm{conv}}}$ & \begin{tabular}{|l} 
Convertor \\
fissions*
\end{tabular} & $\begin{array}{c}\text { Tritons } \\
\mathrm{T}^{*} .\end{array}$ & $\begin{array}{l}\text { Energy } \\
(\mathrm{MeV})^{*}\end{array}$ & ${ }_{M}^{M u l t i p l i c a t i o n}$ & Net Fissile & $\mid \begin{array}{c}\text { Conversion } \\
\text { Ratio CR }\end{array}$ \\
\hline 8 & $\begin{array}{l}9 \\
\\
\end{array}$ & 60 & $\begin{array}{ll}55 \% & \mathrm{UO}_{2} \\
12 \% & \mathrm{SS} \\
33 \% & \mathrm{He}\end{array}$ & .265 & .200 & 1.021 & 163.6 & 11.6 & .263 & 1.29 \\
\hline 19 & $\begin{array}{l}9 \\
\cdots\end{array}$ & 60 & $\begin{array}{ll}55 \% & \mathrm{UC} \\
12 \% & \mathrm{SS} \\
33 \% & \mathrm{He}\end{array}$ & .380 & .242 & 1.070 & 177.7 & 12.6 & .382 & 1.40 \\
\hline 20 & 9 & 60 & $\begin{array}{l}33 \% \mathrm{U}-\mathrm{Me} \text { ta } 1 \\
25 \% \mathrm{SS} \\
42 \% \cdot \mathrm{He}\end{array}$ & .430 & .210 & 1.152 & 179.1 & 12.7 & .152 & 1.15 \\
\hline 21 & 9 & 60 & $\begin{array}{l}40 \% \mathrm{U}-\mathrm{Me} t=1 \\
24 \% \mathrm{SS} \\
36 \% \mathrm{He}\end{array}$ & .485 & .240 & 1.152 & 186.1 & 13.2 & .254 & 1.25 \\
\hline 22 & 19 & 50 & $\begin{array}{l}40 \% \mathrm{U}-\text { Me tal } \\
24 \% \mathrm{SS} \\
36 \% \mathrm{He}\end{array}$ & .485 & .347 & .815 & 160.7 & 1.1 .4 & 1.018 & 2.40 \\
\hline
\end{tabular}

* Per source neutron.

Table 4. Blanket performance for varying convertor zone compositions and thicknesses. The breeder zone

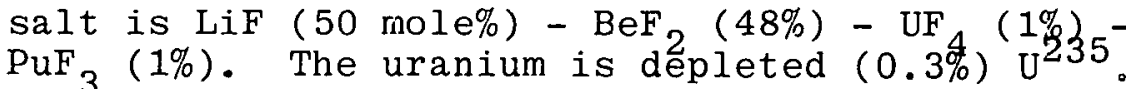




\section{HYBRID BLANKET MODEL}
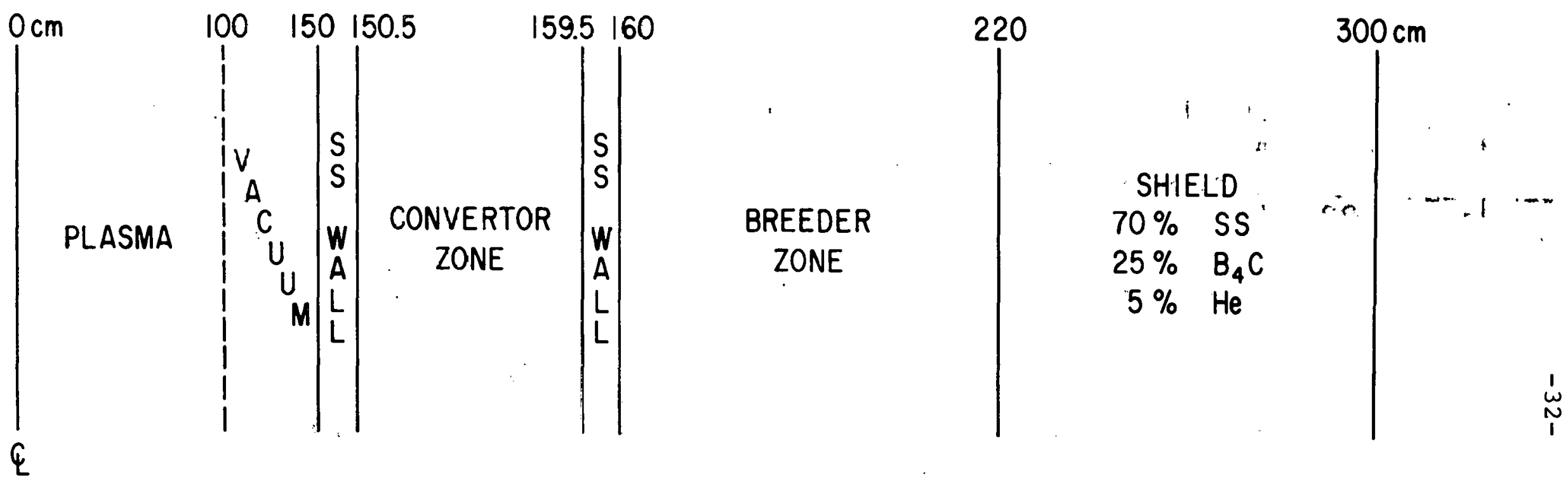

CYLINDRICAL GEOMETRY 

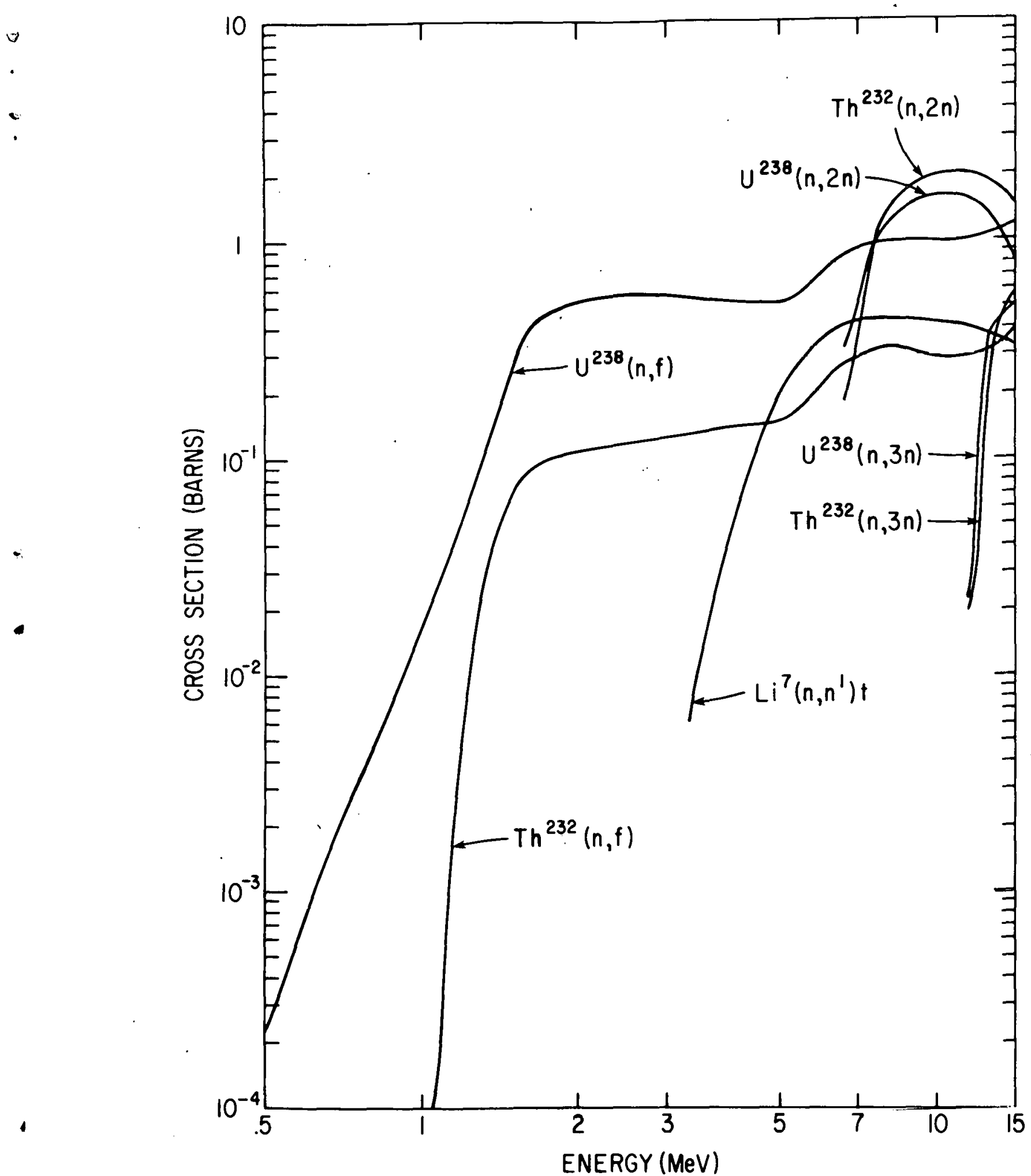

764163

Fig. 2. Approximate behavior of the high energy cross sections of interest in a hybrid blanket. Data is plotted from a 30-group cross section set. 


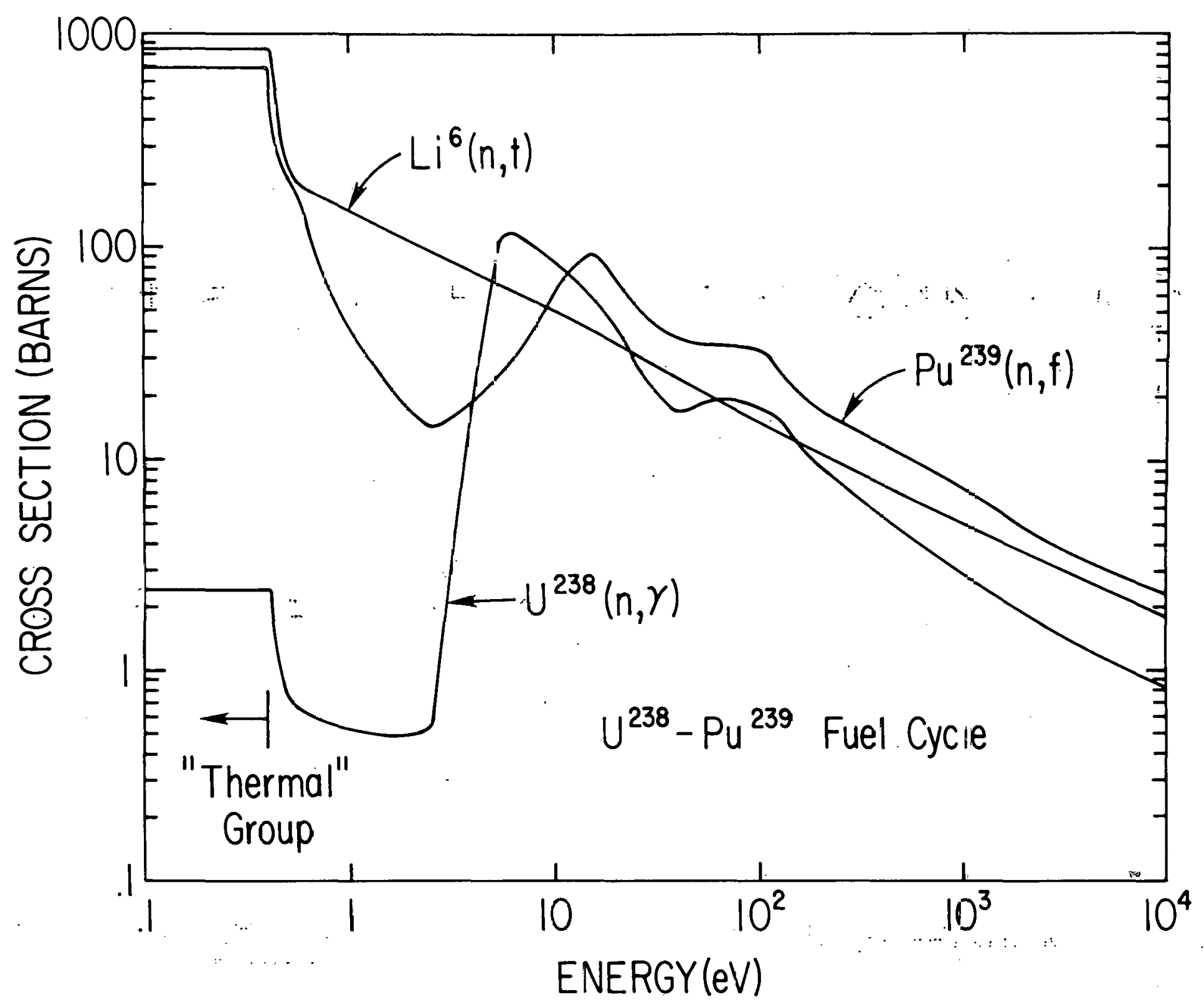

$238 \mathrm{Fig}_{39}{ }^{3}$. Approximate behavigr of the cross sections for the $\mathrm{U}^{238}-\mathrm{Pu}^{239}$ fuel cycle and the $\mathrm{Li}^{6}$ tritium production reaction. Data is plotted from a 30-group cross section set. The "thermal" group is for energies less than $0.414 \mathrm{eV}$. 


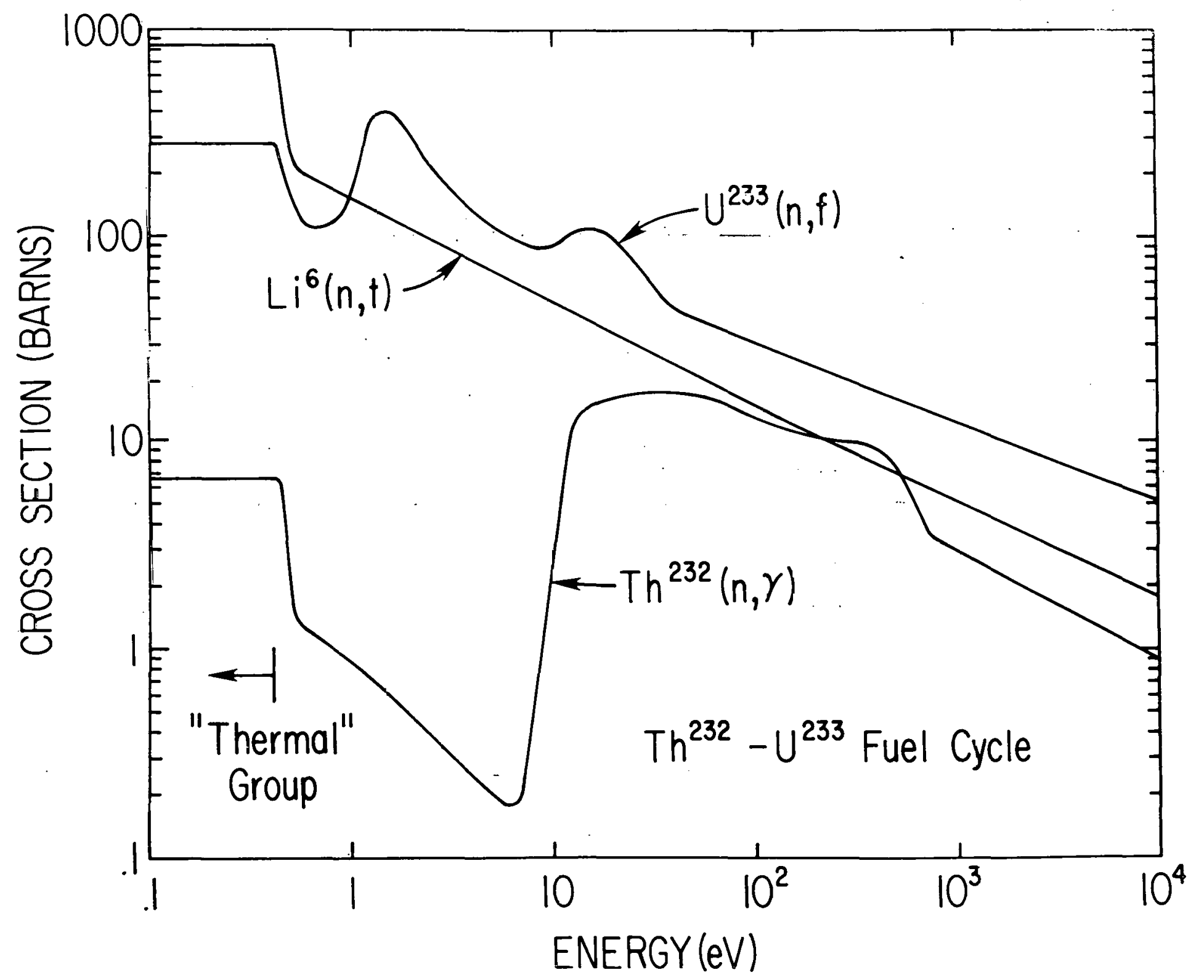
$232^{\mathrm{Fig}}$ 4. Approximate behavior of the cross sections for the 2uel cycle and the $\mathrm{Li}^{6}$ tritium production reaction. Data is plottec from a 30-group cross section set. The "thermal" group is for energies less than $0.414 \mathrm{eV}$. 